\title{
Parasites and global warming: net effects of temperature on an intertidal host-parasite system
}

\author{
A. Studer ${ }^{1, *}$, D. W. Thieltges ${ }^{2}$, R. Poulin ${ }^{1}$ \\ ${ }^{1}$ Department of Zoology, University of Otago, PO Box 56, Dunedin 9054, New Zealand \\ ${ }^{2}$ Royal Netherlands Institute for Sea Research (NIOZ), PO Box 59, 1790 AB Den Burg, Texel, The Netherlands
}

\begin{abstract}
Climate changes, particularly global warming, are likely to impact host-parasite interactions. However, our understanding of the effects of environmental factors on marine host-parasite systems is limited. We conducted a series of laboratory experiments on the effects of temperature on all transmission steps of the intertidal trematode Maritrema novaezealandensis from its first intermediate snail host Zeacumantus subcarinatus to the second intermediate amphipod host Paracalliope novizealandiae. By measuring output of cercarial transmission stages from snails, cercarial survival and infectivity, susceptibility of amphipods to infections, amphipod survival and parasite development within amphipods, we evaluated overall net temperature effects. At low temperatures $\left(<20^{\circ} \mathrm{C}\right)$, transmission was low and amphipod survival unaffected. At intermediate temperatures $\left(20\right.$ to $\left.25^{\circ} \mathrm{C}\right)$, output and infectivity of cercarial transmission stages was at an optimum, which may increase the risk of infection intensity-dependent mortality of amphipods. Also, temperature directly increased amphipod mortality, but accelerated parasite development within amphipods. At high temperatures $\left(\geq 30^{\circ} \mathrm{C}\right)$, transmission of the parasite was reduced (few cercariae, low infectivity), but temperatureinduced mortality of amphipods was most pronounced. Our approach revealed that temperature strongly, but differentially, affects the various steps of the transmission process, pointing to the amphipod as the most vulnerable component. An increased impact of parasites on amphipod populations with global warming is predicted and the possible disruption of the host-parasite system seems realistic under unusual future circumstances such as prolonged heatwaves. We suggest that more holistic studies of host-parasite interactions are essential for a better understanding of potential responses of host-parasite systems to global changes.
\end{abstract}

KEY WORDS: Climate change $\cdot$ Parasitism $\cdot$ Trematoda $\cdot$ Amphipoda $\cdot$ Transmission $\cdot$ Experimental infections

\section{INTRODUCTION}

Parasites are ubiquitous components of the biosphere and constitute an important part of biodiversity (Poulin \& Morand 2000, Marcogliese 2004). Parasites affect not only host individuals, populations and communities, but can play an important role in ecosystem functioning and food-web dynamics (e.g. Sousa 1991, Thomas et al. 2005, Lafferty et al. 2008). This is the case not only for terrestrial and freshwater ecosystems, but also for the marine environment, where parasitism is equally important, but comparatively little studied. A climate-mediated increase in the frequency and sever- ity of disease outbreaks in marine environments has been reported over the last decade (Harvell et al. 1999, Lafferty et al. 2004). This has directly affected vertebrates, invertebrates and plants, with the potential to alter the structure and function of marine ecosystems (Ward \& Lafferty 2004). Given the pivotal role of parasites and pathogens, understanding the potential ramifications of climate change, particularly global warming, on parasitism should be of major concern.

Probably the best-studied marine ecosystems with respect to parasites are intertidal ecosystems, in which digenean trematodes comprise the dominant macroparasite group (Lauckner 1987, Sousa 1991, Mouritsen 
\& Poulin 2002). Typically, they have a complex life cycle involving 3 different hosts. In the definitive host (a vertebrate), adult worms reproduce sexually and eggs are expelled into the environment. First intermediate hosts (molluscs) either ingest the eggs or are actively infected by miracidia that hatch from these eggs. Within the first intermediate host the parasite reproduces asexually, generating large numbers of cercariae, which emerge from their host to infect second intermediate hosts (invertebrates or vertebrates, depending on the trematode species). Cercariae are free-living, short-lived (generally $<24 \mathrm{~h}$ ), non-feeding transmission stages that are directly exposed to ambient conditions (Pietrock \& Marcogliese 2003). After successful infection of a second intermediate host, the cercariae mature into metacercariae. The life cycle is completed when an infected second intermediate host is consumed by a definitive host.

All of these stages of a trematode life cycle are directly affected by temperature (Chubb 1979), in particular the transmission process of the parasite (Poulin 2006). Usually, with increasing temperature, there is an increase in production within, and emergence of cercariae from, the first intermediate hosts (e.g. Mouritsen 2002, Thieltges \& Rick 2006). Infectivity of cercariae (leading to successful transmission to the second intermediate host) increases up to an optimum temperature, whereas survival of cercariae decreases with increasing temperature (Evans 1985, McCarthy 1999). These observations have led to the prediction that global warming might enhance the impacts of trematodes through the increased number of infective stages present in a system (Poulin 2006, Poulin \& Mouritsen 2006).

However, this prediction may be too simplistic, as it is not only the parasites and their free-living stages that are sensitive to temperature changes, but also their hosts (Marcogliese 2001). To anticipate the net effect of an increase in temperature on a host-parasite system, both parasites and hosts have to be considered. Temperature effects on hosts range from a weakening of the host defence and an increase in susceptibility to disease to a boost in immune defences (e.g. Lafferty et al. 2004, Harvell et al. 2009). Temperature can also act as a stressor on hosts and may lead to an increase in parasite-induced mortality (Esch et al. 1975). The impact on individual hosts may then also translate into effects at the population level, which, in turn, may negatively affect the parasite's success at completing its life cycle.

To date, most studies on the effects of temperature on trematodes have only investigated a few aspects of the transmission and infection processes. In addition, most studies have only looked at the short-term responses of parasites to different temperatures (i.e. direct exposure without, or with only very short, previous acclimatisation) and/or focussed on first intermediate hosts. However, responses of parasites to long-term increases in temperature might be different from responses to short-term temperature changes. Also, it is necessary to consider differential effects on hosts and parasites as well as the possible interaction between temperature and parasitism to be able to make more realistic predictions.

In the present study, we used a host-parasite system from the intertidal soft sediment ecosystems of Otago Harbour and surrounding bays (South Island, New Zealand; higher latitude [colder] end of the parasite's geographical distribution) to investigate the net effect of temperature on the different steps of the transmission and infection processes of the trematode Maritrema novaezealandensis, from its first intermediate snail host Zeacumantus subcarinatus to its second intermediate amphipod host Paracalliope novizealandiae. The complex life cycle of $M$. novaezealandensis includes seabirds such as the red-billed gull Larus novaehollandiiae scopulinus as definitive hosts (Martorelli et al. 2004). The mudsnail $Z$. subcarinatus acts as the first intermediate host, from which cercariae (mean body length, including the tail, approx. $170 \mu \mathrm{m}$; Martorelli et al. 2004) emerge under optimal conditions in order to infect a range of second intermediate crustacean hosts including $P$. novizealandiae. Second intermediate hosts have been identified as crucial components of a trematode life cycle (Mouritsen et al. 2005), as mortality of these hosts is highly sensitive to infection intensities (Mouritsen \& Jensen 1997, Meißner \& Bick 1999a,b, Fredensborg et al. 2004). For the completion of a trematode life cycle and the overall assessment of the local impact of a parasite, the second intermediate host might thus be a key component. Due to its high abundance (mean: 350 amphipods $0.5 \mathrm{~m}^{-2}$, range: 4 to 1926 amphipods $0.5 \mathrm{~m}^{-2}$; A. Studer unpubl. data for 1 locality), $P$. novizealandiae is considered an important component of the food web of these intertidal mudflats. Temperature-dependent cercarial output from snails and infection intensity-dependent mortality of amphipod hosts have previously been shown (Fredensborg et al. 2004, 2005), making this an ideal model system to investigate the net effect of temperature on host-parasite interactions and formulate predictions of the potential outcome of this interaction with regard to global warming.

We focussed on understanding the effects of temperature on this trematode-amphipod system by conducting a series of laboratory experiments that address each step of the transmission and infection processes from first to second intermediate hosts (see Fig. 1): (1) long-term cercarial output from first intermediate snail hosts; (2) cercarial survival; (3) cercarial infectivity; (4) 
susceptibility of second intermediate amphipod hosts to infection; (5) survival of infected and uninfected amphipod hosts; and (6) development of the parasite within the amphipod hosts. Our overall objective was to examine the net effects of temperature and to predict how this system is likely to respond to global warming. Although we could not consider the complete life cycle (steps related to the definitive bird host were not included), the investigation of the entire transmission process from first to second intermediate hosts (both poikilotherm), as well as survival of second intermediate hosts and the assessment of long-term responses, allowed more realistic predictions to be made regarding the consequences of global warming on the impact of trematode parasitism in second intermediate host populations.

\section{MATERIALS AND METHODS}

Parasite and host material. First intermediate snail hosts Zeacumantus subcarinatus infected with Maritrema novaezealandenis were collected from the upper intertidal zone of a high prevalence site (Lower

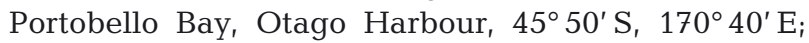
Fredensborg et al. 2006) on a single occasion in October 2008. Snails were screened for infections by incubating them individually in wells with $\sim 3 \mathrm{ml}$ seawater (12-well plate, $23 \times 20 \mathrm{~mm})$ at $25^{\circ} \mathrm{C}$ under constant illumination for 2 to $4 \mathrm{~h}$, and then checking for the presence of emerged cercariae. All snails used in the temperature experiments (see below) were of intermediate size (range: $\sim 11$ to $16 \mathrm{~mm}$ shell length). For experimental infections of second intermediate amphipod hosts, uninfected Paracalliope novizealandiae were collected from Hooper's Inlet (Otago Peninsula) on several occasions 2 to $3 \mathrm{~d}$ before the start of an experiment to allow for adequate acclimatisation to laboratory conditions. As the first intermediate snail host is absent, amphipods from Hooper's Inlet have never been found naturally infected (neither by $M$. novaezealandensis nor by any other metazoan parasite; Fredensborg et al. 2004, Bryan-Walker et al. 2007, present study).

General remarks on the experiments. Tidal flats are subject to extreme fluctuations in abiotic factors, particularly temperature (de Wilde \& Berghuis 1978). Whereas for the main water body in the harbour temperatures are around 7 to $16^{\circ} \mathrm{C}$ (long-term mean minimum and maximum water temperature measured at the Portobello Marine Lab), water temperatures $>30^{\circ} \mathrm{C}$ have been measured in tide pools on the local mudflats during summer (A. Studer unpubl. data). Climate projections for New Zealand suggest an increase of about $0.9^{\circ} \mathrm{C}$ in mean air temperature by 2040 (Ministry for the Environment 2008). Although these general largescale predictions are expected to lead to a similar increase in coastal water temperatures, there are no data available for small-scale localities like the local tidal flats and tide pools used in the present study. Extreme events such as heat waves are also expected to become more frequent. Hence, we decided to base the temperature range used in the experiments on the current temperature range experienced on the mudflats, including the summer extremes, as well as a temperature level beyond that. Experiments therefore included an acclimatisation temperature $(16,20,25$ and $30 \pm 0.5^{\circ} \mathrm{C}$ ) and an incubation temperature $(16,20$, 25, 30 and $34 \pm 0.5^{\circ} \mathrm{C}$ the lowest temperature for the cercariae and amphipod survival experiments was $15 \pm$ $0.5^{\circ} \mathrm{C}$ due to logistical reasons). In these experiments, we focussed on temperature, acknowledging that temperature effects may be due to a combination of heat and levels of dissolved oxygen.

For temperature experiments employing wells, including all experimental infections of amphipods, 96 -well plates $(7 \times 10 \mathrm{~mm}$ wells $)$ were used. In all experiments (except the cercarial output time series), the cercariae used were pooled from 40 snails (either randomly selected snails from stock aquaria kept under variable conditions or acclimatised snails). These snails were incubated in 8 replicate Petri dishes containing $8 \mathrm{ml}$ of aerated seawater at the next higher temperature from their acclimatisation temperature (16 to $20^{\circ} \mathrm{C}, 20$ to $25^{\circ} \mathrm{C}$ etc., or $25^{\circ} \mathrm{C}$ for the snails from the stock aquaria) for $1 \mathrm{~h}$ under constant illumination. After removal of the snails, seawater containing the emerged cercariae was combined and carefully mixed (see below). This allowed a genetically mixed array of cercariae to be used in the experiments. To assess the number of cercariae added per volume of each mixture, cercariae in 10 aliquots were counted. All amphipods used were measured, grouped into size classes $(2.5,3.0,3.5,4.0,4.5 \pm 0.25$, and $\geq 4.5 \mathrm{~mm})$ and sexed prior to their dissection under a dissecting microscope. General husbandry of snails and amphipods included weekly changes of water (long-term shedding experiment) and feeding with Ulva sp. algae ad libitum. Prior to all statistical analyses (see details under each section below) we tested for assumptions regarding parametric tests and for differences between replicates. Data were transformed or nonparametric tests were used where assumptions were violated. Data are presented as means \pm SE unless otherwise indicated.

Output of Maritrema novaezealandensis cercariae from first intermediate snail hosts. Long-term cercarial output (Fig. 1, Step 1) was assessed by counting the number of cercariae released by snails acclimatised to different temperatures during weekly incubations over 


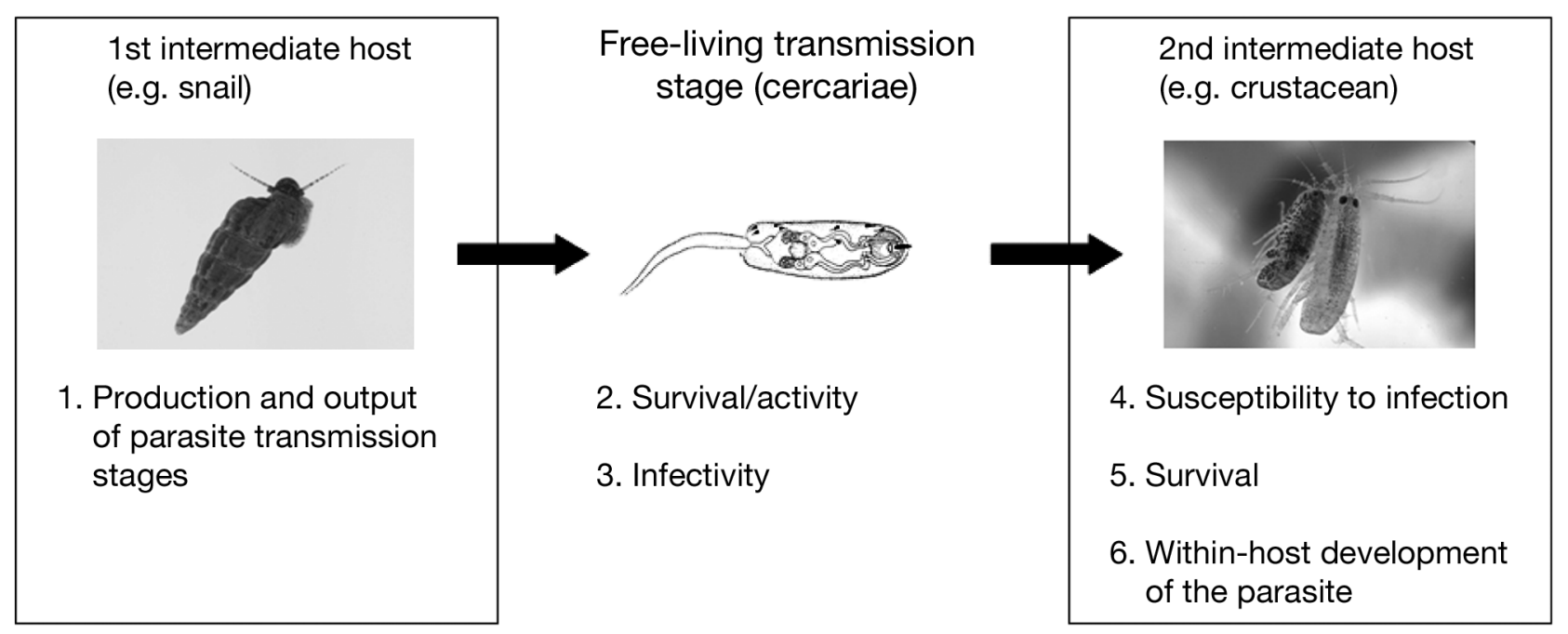

Fig. 1. Conceptual model of the different steps of the transmission process studied. Note: first intermediate snail host Zeacumantus subcarinatus, cercariae of the trematode Maritrema novaezealandensis and second intermediate amphipod host Paracalliope novizealandiae are not to scale. Photos of snail and amphipod courtesy of A. Köhler

a period of $8 \mathrm{wk}$. Snails were marked individually using numbered plastic tags (The Bee Works) to allow repeated counts of the number of cercariae released by individual snails over time. In an attempt to clear the parasite tissue within these snails of fully developed cercariae, snails were first incubated at $25^{\circ} \mathrm{C}$ for $24 \mathrm{~h}$ under constant illumination, after which cercarial output has been found to be much reduced for several days when continuously kept under these conditions (A. Studer unpubl. data). Snails were then distributed into 2 replicate aquaria at each of $16,20,25$ and $30^{\circ} \mathrm{C}$ (temperatures $\pm 0.5^{\circ} \mathrm{C}, \mathrm{n}=28$ per temperature level). After $1 \mathrm{wk}$ at the respective acclimatisation temperatures, half of the snails were incubated for $24 \mathrm{~h}$ at this same temperature $\left(16\right.$ at $16^{\circ} \mathrm{C}, 20$ at $20^{\circ} \mathrm{C}, 25$ at $25^{\circ} \mathrm{C}$ and 30 at $30^{\circ} \mathrm{C}$; equal temperature treatment), while the other half were incubated at one temperature level higher $\left(16\right.$ at $20^{\circ} \mathrm{C}, 20$ at $25^{\circ} \mathrm{C}, 25$ at $30^{\circ} \mathrm{C}$ and 30 at $34^{\circ} \mathrm{C}$; temperature boost treatment; all incubations under constant illumination). The temperature boost was meant to simulate the higher temperatures that are experienced by snails at low tide on hot sunny days, occasions thought to trigger emergence of readily developed cercariae from snails (Fredensborg et al. 2004). For the incubations, snails were individually placed in $1.5 \mathrm{ml}$ Eppendorf tubes filled with $1 \mathrm{ml}$ aerated seawater at the respective temperature. To preserve the emerged cercariae after removal of the snails, tubes were centrifuged ( $5 \mathrm{~min}, 20817 \times \mathrm{g}$ ), and $900 \mu \mathrm{l}$ of the seawater was replaced with $70 \%$ ethanol. The discarded water was checked for the presence of cercariae. This procedure was repeated weekly for $7 \mathrm{wk}$, except that subsequent incubations were shortened to $6 \mathrm{~h}$ to prevent any potential decay of cercariae at high temperatures and to provide a realistic time frame of potential shedding in relation to the tides. Samples containing preserved cercariae were counted under a dissecting microscope. A general linear model (GLM) was used to determine the effect of the acclimatisation and incubation temperatures (incubation equal or not equal to acclimatisation temperature) on the log average output of cercariae per weekly shedding event.

Survival of cercariae. This experiment monitored survival and activity of cercariae (Fig. 1, Step 2) at different temperatures, using cercariae from infected snails that were acclimatised to different temperature levels (15 and 16, 20, 25 and $30 \pm 0.5^{\circ} \mathrm{C}$ ) for several weeks. A cercarial mixture was obtained for the different acclimatisation temperatures (see above). Snails acclimatised to 15 and $30^{\circ} \mathrm{C}$ did not shed enough cercariae to be included in the experiment. For the 20 and $25^{\circ} \mathrm{C}$ acclimatisation levels, groups of $\sim 20$ to 25 cercariae (corresponding to $40 \mu \mathrm{l}\left[20^{\circ} \mathrm{C}\right]$ and $25 \mu \mathrm{l}\left[25^{\circ} \mathrm{C}\right]$ of the cercarial mixtures) were then transferred into wells of a 96-well plate and incubated under constant illumination at $15,20,25,30$ and $34^{\circ} \mathrm{C}$ (12 wells in 2 replicate well plates per temperature level; volume of water in wells standardised to $50 \mu \mathrm{l}$ ). The survival of the cercariae was checked $2,4,7,12,22$ and 26 h postemergence by assessing the number of cercariae that were fully active, sluggishly motile, or immotile/dead. The data were analysed using a repeated measures ANOVA to determine the effect of the acclimatisation and incubation temperatures on the proportions of fully active cercariae (arcsine-square root transformed) 2, 4, 7 and $12 \mathrm{~h}$ post-emergence.

Infectivity of cercariae. Infectivity (Fig. 1, Step 3) of cercariae was assessed by comparing their success at 
infecting amphipod hosts. For these experimental infections, 40 uninfected amphipods were put individually in wells of 2 replicate well plates filled with $75 \mu \mathrm{l}$ seawater at the respective temperature. A cercarial mixture was obtained from acclimatised snails (see above). To each well, $50 \mu \mathrm{l}$ of the cercarial mixture from snails acclimatised at 16,20 or $30^{\circ} \mathrm{C}$ (corresponding to an addition of an average of 3, 25 and 20 cercariae per amphipod), or $25 \mu \mathrm{l}$ (plus $25 \mu \mathrm{l}$ of seawater to standardise the volumes) of the cercarial mixture from snails acclimatised at $25^{\circ} \mathrm{C}$ (corresponding to an addition of $\sim 35$ cercariae per amphipod) was added. Two different approaches were used to investigate infectivity of cercariae. First, for all acclimatisation temperatures, experimental infections were conducted to assess infectivity of the cercariae at the acclimatisation temperature, compared with the infectivity of these cercariae one temperature level higher (16 at 16 and $20^{\circ} \mathrm{C}, 20$ at 20 and $25^{\circ} \mathrm{C}$, etc.). Second, the infectivity of cercariae from snails acclimatised to $20^{\circ} \mathrm{C}$ was assessed at all experimental temperature levels $(16,20$, 25,30 and $34^{\circ} \mathrm{C}$ ). The 2 approaches were conducted in order to assess the importance of long-term acclimatisation versus short-term exposure on the infectivity of the cercariae. The incubation period was $2 \mathrm{~h}$ under constant illumination. Unlike previous studies (Fredensborg et al. 2004, Bryan-Walker et al. 2007), the shorter incubation period for the experimental infections was chosen in order to reduce amphipod mortality at high temperatures. After incubation, amphipods were placed in 2 replicate groups per treatment in small containers (approx. $300 \mathrm{ml}$ aerated seawater) and left for 1 to $2 \mathrm{~d}$ at $16^{\circ} \mathrm{C}$. Amphipods were then dissected to assess the proportions of cercariae that successfully infected the amphipods. A GLM was used to assess the effect of acclimatisation and incubation temperatures on the proportion of cercariae (arcsinesquare root transformed) that successfully infected amphipods.

Susceptibility of amphipods to infections. Susceptibility of second intermediate hosts to infection (Fig. 1, Step 4) was investigated by exposing amphipods to different temperatures prior to adding non-acclimatised cercariae, and then comparing the infection success of the cercariae in these hosts. Groups of 17 amphipods (2 replicate groups per temperature level) were put through an acclimatisation series at $1 \mathrm{~h}$ steps until reaching the final temperature level $(16,20,25,30$ and $34^{\circ} \mathrm{C}$, all amphipods handled similarly). Amphipods were then distributed into wells containing $75 \mu \mathrm{l}$ aerated seawater at the respective temperature. From the cercarial mixture generated (from snails kept in a stock aquarium), $30 \mu \mathrm{l}$ was added to each well that contained an amphipod ( 20 cercariae per amphipod). Well plates were then incubated under constant illum- ination at the different temperatures for $2 \mathrm{~h}$ and amphipods were subsequently dealt with as described for the infectivity experiment (Step 3). A GLM was used to determine the effect of the incubation temperature on the proportion of cercariae (arcsine-square root transformed) that successfully infected the amphipods.

Survival of infected and uninfected amphipods and development of parasites within amphipod hosts. Infected and uninfected amphipods were exposed to different temperatures and their survival (Fig. 1, Step 5) was monitored over a $12 \mathrm{~d}$ period. Amphipods $(\mathrm{n}=$ 400) were placed individually in wells filled with $75 \mu \mathrm{l}$ aerated seawater (40 amphipods in each of 2 replicate well plates per temperature level). A cercarial mixture was prepared from snails kept in stock aquaria. Of this mixture, $50 \mu \mathrm{l}$ was added to half of the wells (corresponding to an addition of $\sim 25$ to 30 cercariae per amphipod), and the same volume of pure seawater was added to the controls. Well plates were incubated for $2 \mathrm{~h}$ at $25^{\circ} \mathrm{C}$ under constant illumination to allow the cercariae to infect the amphipods. Amphipods were then transferred into containers filled with $300 \mathrm{ml}$ aerated seawater and stored overnight at $15^{\circ} \mathrm{C}$ to allow the cercariae to fully penetrate the hosts. The following day, infected amphipods and uninfected control amphipods were put through an acclimatisation series ( $1 \mathrm{~h}$ at every temperature level; all amphipods handled similarly) and subsequently were placed into 2 replicate aquaria ( $6.5 \mathrm{l}$, half filled) at the final experimental temperature level $\left(15,20,25,30\right.$ and $\left.34 \pm 0.5^{\circ} \mathrm{C}\right)$. Survival was subsequently monitored 2 to 3 times a day. Dead amphipods were dissected to assess the infection status, infection intensity and the developmental stage of the parasites (Fig. 1, Step 6); developmental stages of metacercariae were classified as early immature, late immature, early cyst and mature cyst, according to Keeney et al. (2007). After 12 d, all remaining amphipods were sacrificed.

For the statistical analyses, Kruskal-Wallis tests were used to compare the survival time of the amphipods (only those that died during the experiment) between temperature levels and between amphipod size classes (data not normally distributed), and Mann-Whitney $U$-tests were used to determine the significance of the effect of infection status and sex of the amphipods. A Spearman's rank correlation was used to assess the relationship between infection intensity (number of metacercariae per amphipod) and survival time in the experiment. A survival analysis was carried out comparing the survival of all amphipods in the experiment at different temperatures $\left(\chi^{2}\right)$. Further survival analyses were run to assess the survival of infected and uninfected amphipods separately at 20 and $25^{\circ} \mathrm{C}$ (Cox's F-test). 


\section{RESULTS}

\section{Cercarial output from snails}

The total average output of cercariae per snail over the entire $8 \mathrm{wk}$ at each acclimatisation/incubation level varied substantially, with a mean of $8.1 \pm 3.9$ cercariae per snail at $16 / 16^{\circ} \mathrm{C}, 107.1 \pm 34.2$ at $16 / 20^{\circ} \mathrm{C}$, $170.1 \pm 68.6$ at $20 / 20^{\circ} \mathrm{C}, 615.9 \pm 181.4$ at $20 / 25^{\circ} \mathrm{C}, 592.8$ \pm 200.2 at $25 / 25^{\circ} \mathrm{C}, 1483.2 \pm 339.9$ at $25 / 30^{\circ} \mathrm{C}, 127.4 \pm$ 56.0 at $30 / 30^{\circ} \mathrm{C}$ and $531.5 \pm 142.5$ at $30 / 34^{\circ} \mathrm{C}(\mathrm{n}=14$, range: 0 to 1177 cercariae per snail per incubation period). These differences were significant among acclimatisation levels (Table 1), and cercarial production over the whole period was highest for the snails kept at $25^{\circ} \mathrm{C}$ (Fig. 2). Cercarial production was similar at 20 and $30^{\circ} \mathrm{C}$, whereas at $16^{\circ} \mathrm{C}$ it was consistently low (Fig. 2). The temperature boost during snail incubation (acclimatisation level < incubation level) also had a significant effect on the average and total output of

Table 1. Effect of acclimatisation temperature $(16,20,25$ and $30^{\circ} \mathrm{C}$ ) and temperature boost (incubation temperature $>$ acclimatisation temperature, compared with incubation temperature $=$ acclimatisation temperature) on the average number of Maritrema novaezealandensis cercariae released from infected snail hosts over the entire period of the experiment (one $24 \mathrm{~h}$ incubation followed by 7 weekly $6 \mathrm{~h}$ incubations; log-transformed; $\mathrm{n}=28$ per acclimatisation temperature). Results of the general linear model

\begin{tabular}{|lccrr|}
\hline Factor & df & MS & $F$ & p \\
\hline Acclimatisation temperature & 3 & 1.43 & 13.54 & $<0.001$ \\
Temperature boost & 1 & 1.67 & 15.75 & $<0.001$ \\
Acclimatisation $\times$ Boost & 3 & 0.06 & 0.55 & 0.649 \\
Error & 56 & 0.11 & & \\
\hline
\end{tabular}

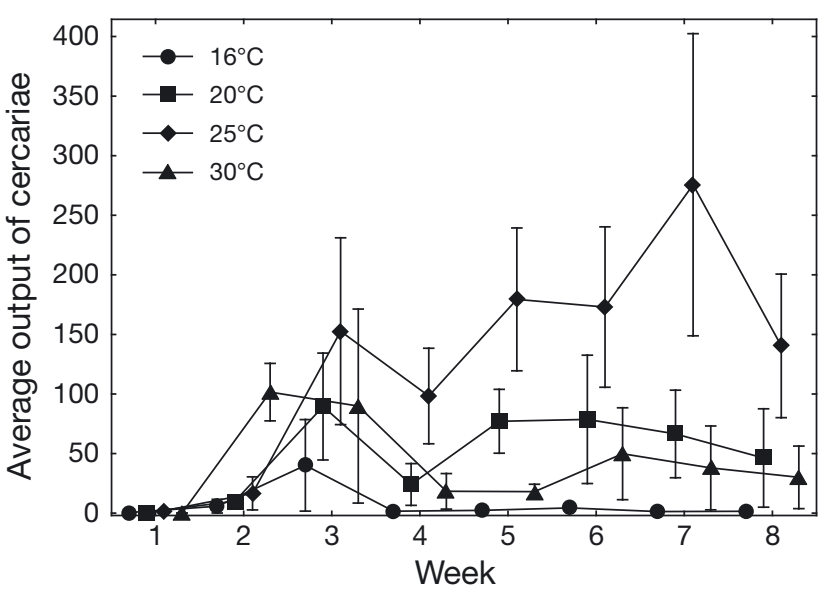

Fig. 2. Maritrema novaezealandensis. Mean \pm SE output of cercariae from infected snail Zeacumantus subcarinatus hosts over 8 weekly incubations for 4 acclimatisation temperatures ( $\mathrm{n}=28$ per temperature) cercariae per snail (Table 1) at all temperature levels (GLM, temperature boost: $F_{1,104}=28.37$ and 27.43, respectively, $\mathrm{p}<0.001$ for both total and average output; Fig. 3). There was no significant difference in shell length among the snails used in the different replicates and treatments ( $\mathrm{n}=112$, size range 11.0 to $15.7 \mathrm{~mm}$; 1 -way ANOVA, $F_{15,96}=1.23, \mathrm{p}=0.22$ ).

\section{Cercarial survival}

Full activity decreased steadily with increasing temperature. Incubation temperature, time and their interaction (but not acclimatisation temperature or any associated interaction) had a significant effect on the proportion of fully active cercariae (Table 2). Full activity of cercariae ceased within $12 \mathrm{~h}$ post-emergence except for cercariae incubated at $15^{\circ} \mathrm{C}$ (Fig. 4).

\section{Infectivity of cercariae}

For cercariae from snails acclimatised to the range of experimental temperatures, infectivity significantly differed between acclimatisation levels (GLM, $F_{3,312}=$ $34.36, \mathrm{p}<0.001)$. The optimum temperature for successful infection was $25^{\circ} \mathrm{C}$, with 30 and $16^{\circ} \mathrm{C}$ showing the lowest proportions of cercariae successfully infecting an amphipod host (Fig. 5). The percentage of infected amphipods was 38,100, 100 and $99 \%$ at 16, 20, 25 and $30^{\circ} \mathrm{C}$ ( $\mathrm{n}=40$ for each acclimatisation temperature). Mean infection intensities varied from $0.5 \pm 0.1$ $\left(16^{\circ} \mathrm{C}\right)$ to $6.0 \pm 0.4\left(20^{\circ} \mathrm{C}\right), 14.2 \pm 0.7\left(25^{\circ} \mathrm{C}\right)$ and $4.2 \pm 0.3$

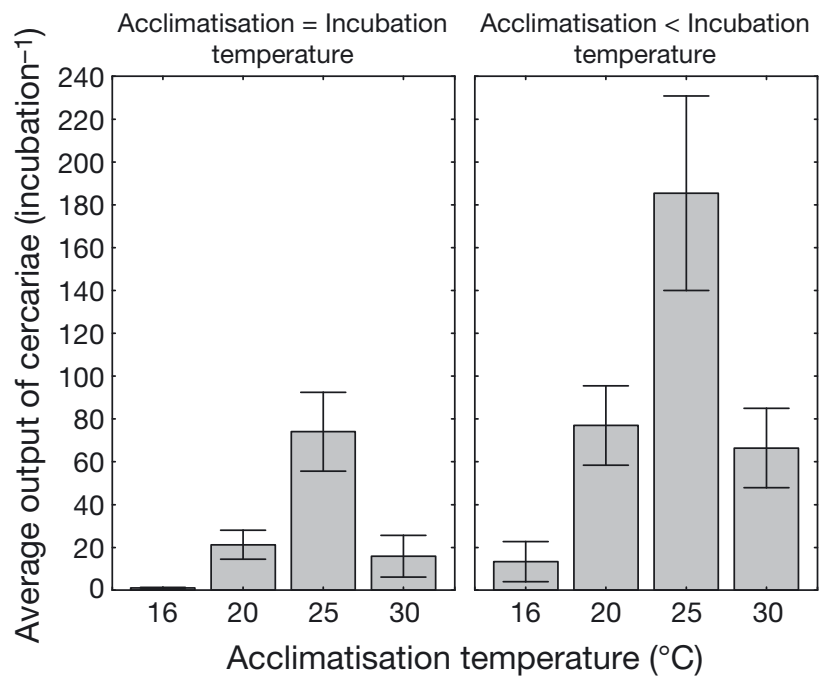

Fig. 3. Maritrema novaezealandensis. Effect of the temperature boost (acclimatisation < incubation temperature) on the mean output of cercariae per weekly incubation $(n=14$ per treatment). Error bars are $\pm \mathrm{SE}$ 
Table 2. Effect of acclimatisation $\left(15 / 16,20,25\right.$ and $\left.30^{\circ} \mathrm{C}\right)$ and incubation $\left(15 / 16,20,25,30\right.$ and $\left.34^{\circ} \mathrm{C}\right)$ temperatures on the activity of Maritrema novaezealandensis cercariae (proportion of fully active; arcsine-square root transformed; $\mathrm{n}=12$ ). Results of the repeated measures ANOVA (with multivariate within-subjects results)

\begin{tabular}{|lcrrr|}
\hline Factor & df & MS & $F$ & $\mathrm{p}$ \\
\hline Between subjects & & & & \\
Acclimatisation temperature & 1 & 0.02 & 0.03 & 0.854 \\
Incubation temperature & 4 & 3.07 & 5.23 & 0.001 \\
Acclimatisation $\times$ Incubation & 4 & 0.34 & 0.58 & 0.675 \\
Error & 110 & 0.59 & & \\
Within subjects & & & & \\
Time & 3 & 10.62 & 66.56 & $<0.001$ \\
Time $\times$ Acclimatisation & 3 & 0.04 & 1.39 & 0.249 \\
Time $\times$ Incubation & 12 & 0.44 & 7.84 & $<0.001$ \\
Time $\times$ Acclimatisation & 12 & 0.03 & 0.82 & 0.627 \\
$\quad \times$ Incubation & & & & \\
Error (Time) & 330 & 0.07 & & \\
\hline
\end{tabular}

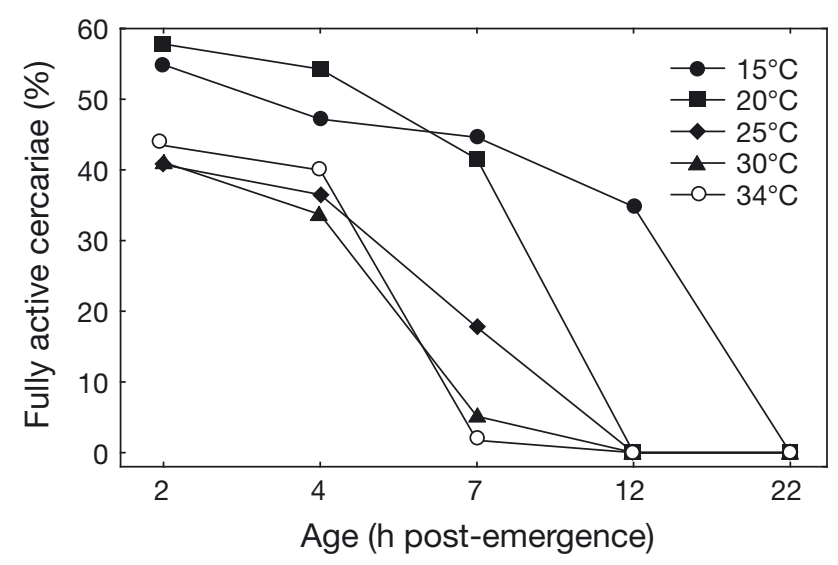

Fig. 4. Maritrema novaezealandensis. Percentage of fully active cercariae at $15,20,25,30$ and $34^{\circ} \mathrm{C}$ measured $2,4,7,12$ and $22 \mathrm{~h}$ post-emergence $(\mathrm{n}=12$ per temperature)

$\left(30^{\circ} \mathrm{C}\right)$ parasites per amphipod. No significant difference was found in the infectivity of cercariae that were incubated at their respective acclimatisation level compared to the cercariae that were incubated at one temperature level higher $\left(\mathrm{GLM}, F_{1,312}=2.69, \mathrm{p}=0.10\right)$.

In contrast to the results described above, infectivity of cercariae snails acclimatised at $20^{\circ} \mathrm{C}$ and then exposed to all experimental temperatures did not vary significantly between incubation temperatures (GLM, $\left.F_{4,195}=0.91, \mathrm{p}=0.46\right)$. Infection status of the amphipods varied only slightly between the incubation temperatures $(98,100,100,93$ and $100 \%$ infected amphipods at $16,20,25,30$ and $34^{\circ} \mathrm{C} ; \mathrm{n}=40$ for each temperature). The mean proportion of cercariae successfully infecting an amphipod was $0.29 \pm 0.01$ and mean infection intensity was $5.8 \pm 0.3$ parasites per amphipod $(n=200)$. For both experiments, size and sex of the amphipods had no significant effect on infectivity of cercariae.



Fig. 5. Maritrema novaezealandensis. Infectivity of cercariae. Mean $( \pm \mathrm{SE})$ percentage of cercariae from snails acclimatised to 4 different temperatures successfully infecting an amphipod Paracalliope novizealandiae host $(\mathrm{n}=40$ for each temperature)

\section{Susceptibility of amphipods}

There was no significant difference in the susceptibility of amphipods regarding either the number of parasites within the hosts or the proportion of cercariae successfully infecting amphipods (mean: $0.27 \pm 0.01 ; \mathrm{n}=$ 170) when exposed to different temperatures prior to and during the experimental infection (GLM, log number of parasites: $F_{4,165}=1.61, \mathrm{p}=0.17$; arcsine-square root proportion of successful cercariae: $\left.F_{4,165}=2.10, \mathrm{p}=0.08\right)$. Of all amphipods in the experiment $(n=170), 99 \%$ were infected by at least 1 cercaria $\left(100 \%\right.$ at 16,20 and $25^{\circ} \mathrm{C}$, $97 \%$ at 30 and $34^{\circ} \mathrm{C} ; \mathrm{n}=34$ for each temperature), and the overall mean infection intensity was $5.3 \pm 0.3$ parasites per amphipod. Size and sex of amphipods did not differ between treatments and had no significant effect on the proportion of cercariae that successfully infected an amphipod host (1-way ANOVA, sex: $F_{1,168}=0.03, \mathrm{p}=$ 0.87 ; size classes: $F_{4,165}=2.16, \mathrm{p}=0.08$ ).

\section{Survival of infected and uninfected amphipods}

The average time of the amphipods in the experiment until death varied significantly between temperatures, with time until death decreasing with increasing temperatures (Kruskal-Wallis, $H_{3, \mathrm{n}=252}=216.24$, $\mathrm{p}<$ $0.001)$. Infection status had no significant effect on the average time until death (Mann-Whitney $U$-test, $Z=$ $0.29, \mathrm{p}=0.77$ ), nor did amphipod sex or size (sex: Mann-Whitney $U$-test, $Z=0.49, \mathrm{p}=0.62$; size classes: Kruskal-Wallis, $H_{4, \mathrm{n}=244}=1.83, \mathrm{p}=0.77$ ). There was a 
weak, positive correlation between infection intensity and survival time in the experiment (Spearman's rank correlation coefficient $=0.12$ ), with highly infected individuals surviving for slightly longer (mean survival time of amphipods in the experiment: amphipods with no parasites, $3.3 \pm 0.3 \mathrm{~d}$; with 1 parasite, $3.7 \pm 0.9 \mathrm{~d}$; with $>1$ parasite, $3.9 \pm 0.5 \mathrm{~d}$ ). A total of 376 amphipods were recovered during the experiment (203 females, 169 males, 4 unsexed). Overall, $48 \%$ of the amphipods were infected $\left(54 \%\right.$ at $16^{\circ} \mathrm{C}, \mathrm{n}=76 ; 43 \%$ at $20^{\circ} \mathrm{C}, \mathrm{n}=$ $76 ; 49 \%$ at $25^{\circ} \mathrm{C}, \mathrm{n}=70 ; 41 \%$ at $30^{\circ} \mathrm{C}, \mathrm{n}=78 ; 53 \%$ at $34^{\circ} \mathrm{C}, \mathrm{n}=76$ ). Mean infection intensities did not vary significantly between temperatures (overall mean infection intensity: $5.3 \pm 0.3$; GLM, $\log$ number of parasites: $F_{4,371}=1.66, \mathrm{p}=0.16$ ).

Survival of amphipods at various temperatures differed significantly $\left(\chi^{2}=226.72, \mathrm{df}=4, \mathrm{p}<0.001\right)$. All amphipods at $34^{\circ} \mathrm{C}$ were dead within $2 \mathrm{~h}$, whereas the survival of amphipods at $30^{\circ} \mathrm{C}$ was approximately $2 \mathrm{~d}$, regardless of their infection status (Fig. 6). Survival at 20 and $25^{\circ} \mathrm{C}$ was similar, with the infected amphipods surviving slightly longer; however, this was only significant at $20^{\circ} \mathrm{C}$ (survival analysis, Cox's F-test, infection status at $20^{\circ} \mathrm{C}: F_{26,50}=2.16, \mathrm{p}=0.001 ; 25^{\circ} \mathrm{C}: F_{58,62}=$ $1.18, \mathrm{p}=0.26)$. There was almost no mortality in infected or uninfected amphipods kept at $15^{\circ} \mathrm{C}$.

\section{Parasite development within the amphipod host}

The temperature at which amphipods were kept had a strong effect on the development of the parasites. Metacercariae from amphipods kept at $20^{\circ} \mathrm{C}(\mathrm{n}=259)$ were mostly at late immature (59\%) and early cyst stages $(39 \%)$ (those recovered from dead amphipods both during and at the end of the experiment). When kept at $25^{\circ} \mathrm{C}, 29 \%$ of the metacercariae completed development during the course of the $12 \mathrm{~d}$ experiment ( $\mathrm{n}=264$ ). The metacercariae recovered from amphipods incubated at 30 and $34^{\circ} \mathrm{C}$ (maximum survival of $2 \mathrm{~d}$ and $2 \mathrm{~h}$, respectively) were still in the early immature stage $(100 \%$ for both; $n=125$ and 221, respectively). Similarly, metacercariae recovered from amphipods kept at $15^{\circ} \mathrm{C}$ and sacrificed after $12 \mathrm{~d}$ were between the early immature and late immature stages $(\mathrm{n}=225)$.

\section{DISCUSSION}

Parasites are strongly influenced by environmental conditions and rely on their hosts for completion of the life cycle. A change in these conditions, particularly temperature, is very likely to differentially affect the parasite, the host and/or their interaction. The outcome of such changes on host-parasite relationships in marine systems has rarely been assessed. The present study experimentally investigated the effects of temperature on an intertidal trematodeamphipod system, incorporating aspects of the parasite and the host in order to make more realistic predictions about the potential impact of global warming on trematode parasitism.
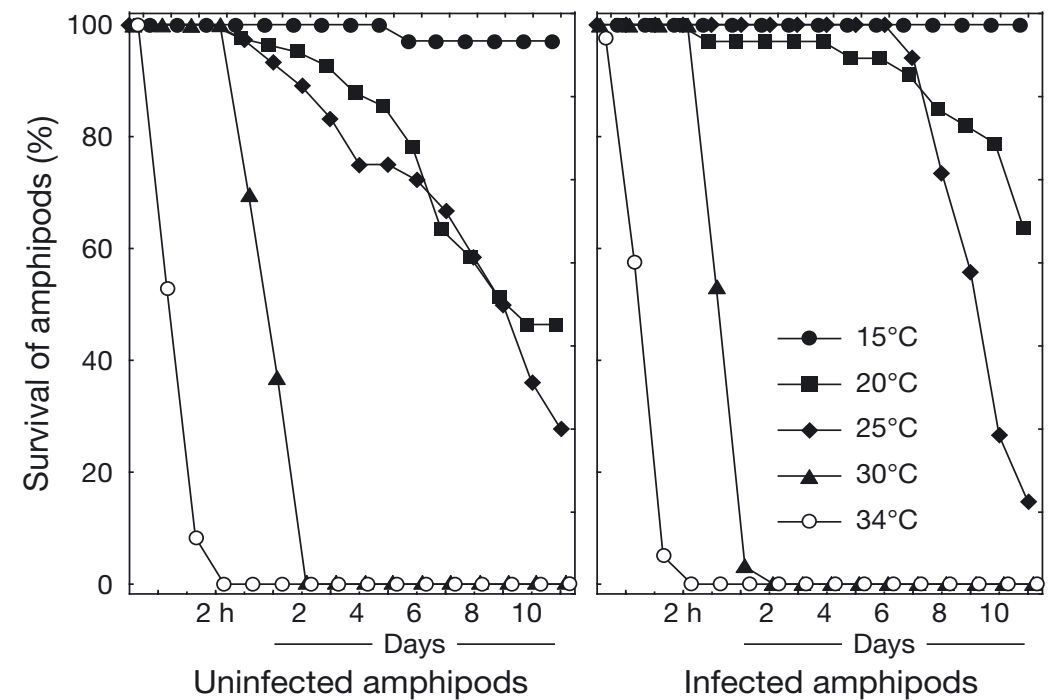

Fig. 6. Paracalliope novizealandiae. Survival (\%) of infected and uninfected amphipod hosts at $15,20,25,30$ and $34^{\circ} \mathrm{C}$ over a $12 \mathrm{~d}$ period. Note that the $x$-axis is not to scale: the first intervals represent 30, 90, 120 and $150 \mathrm{~min}$, whereas all following intervals represent days

\section{Effects on the parasite}

With increasing temperatures, the production and output of Maritrema novaezealandensis transmission stages (cercariae) from first intermediate snail hosts Zeacumantus subcarinatus increased up to an optimum temperature. Temperature has been shown to trigger the emergence of cercariae and to accelerate the production of new cercariae within first intermediate hosts (e.g. Ataev 1991). Previous studies have also reported similar hump-shaped production patterns (e.g. Thieltges \& Rick 2006). However, the present study is one of very few assessing long-term cercarial production and output. Our results suggest that raising temperatures could cause a considerable increase in cercarial production and emergence, which should be of particular relevance for the ongoing and predicted increase in winter temperatures, 
but also for more frequent heat waves in summer which would, as long as temperatures lie within the optimal range for the parasite, result in more infective stages being present in an ecosystem.

Survival of cercariae decreased steadily with increasing temperature, as described in other studies (e.g. Evans 1985, McCarthy 1999, Mouritsen 2002). Increasing temperatures seem to directly affect the activity of cercariae, leading to a faster depletion of their finite energy reserves (Pechenik \& Fried 1995). Infectivity increased with temperature until dropping off at high temperatures. It has been suggested that as cercarial activity increases, so does the number of contacts with a potential host per unit time (Evans 1985). At high temperatures, the decrease in infectivity results from the rapid depletion of the limited energy reserves, so that reserves might not be sufficient to allow successful penetration and subsequent establishment in the host. However, in the present study, infectivity was different for cercariae that were produced in snails acclimatised to different temperatures, but not when comparing cercariae from one acclimatisation temperature that were exposed to the range of experimental temperatures. The most likely explanation for this discrepancy is that cercarial density within snails affects the per capita infectivity rate of cercariae. As shown previously (Evans \& Gordon 1983), per capita infectivity increases with increasing cercarial density up to a threshold before dropping off. Therefore, temperature has not only a direct effect on cercarial production, but also an indirect effect on the success of cercariae at infecting second intermediate hosts. This notwithstanding, it should be noted that the long-term acclimatisation in our experiment led to different numbers of cercariae being used for the different treatments, which may account for some of the pattern observed, especially in the case of the coldest treatment.

The overall transmission success or efficiency is a measure that combines cercarial survival and infectivity. Previous studies have shown that transmission efficiency can be relatively high over a wide range of temperatures; at low temperatures, low infectivity is offset by low mortality, whereas at high temperatures, higher infectivity compensates for higher mortality (Evans 1985, McCarthy 1999). The results from the present study indicate a similar pattern, except that at very high temperatures, both survival and infectivity are negatively affected. Assuming that cercarial survival and infectivity are counterbalanced up to a certain threshold (based on our results estimated to lie between 25 and $30^{\circ} \mathrm{C}$ for Maritrema novaezealandensis), rising temperatures up to that threshold would nevertheless lead to an increase in the number of cercariae present in a system (through cercarial production and emergence). High infection intensities with
M. novaezealandensis induce mortality in amphipod hosts (Fredensborg et al. 2004) and increasing temperatures are likely to cause more frequent exposures of amphipods to large numbers of cercariae, thereby increasing the risk of parasite-induced host mortality. Rising temperatures beyond this threshold would negatively affect cercarial emergence, survival, and infectivity and, therefore, the transmission success of this parasite.

\section{Effects on the host}

Susceptibility of amphipods was the only step of the transmission process studied which was not significantly affected by temperature. By contrast, amphipod survival was strongly affected by temperature. Survival of amphipods was dramatically reduced at $34^{\circ} \mathrm{C}$ and, because amphipod survival was even lower than cercarial survival, amphipods are considered the most vulnerable component of all aspects of the trematode-amphipod system studied here. At high temperatures (30 and $34^{\circ} \mathrm{C}$ ), amphipod hosts died regardless of their infection status. At intermediate temperatures (20 to $25^{\circ} \mathrm{C}$ ), a more subtle effect of the parasite on host survival was apparent. Although only significant at $20^{\circ} \mathrm{C}$, infected amphipods had a slightly higher survival than uninfected amphipods. This had already been observed in a previous study, where even amphipods with relatively high infection intensities had a higher survival rate towards the end of the experimental period than individuals from the control group (Fredensborg et al. 2004). This is rather surprising, given that, within the amphipod hosts, the parasite's development is accompanied by an approximate 200 -fold increase in volume. Infection intensities in our experiments were relatively low, but are representative of the average infection intensity found in some naturally infected populations (Fredensborg et al. 2004, Bryan-Walker et al. 2007).

\section{Effects on parasite development within the amphipod host}

Temperature greatly affected parasite development within the second intermediate host. Martorelli et al. (2004) reported recovery of mature metacercariae from experimentally infected amphipods after 4 to $5 \mathrm{wk}$ (at an unspecified temperature). In the present study, a substantial number of parasites were able to complete development at $25^{\circ} \mathrm{C}$ within less than $12 \mathrm{~d}$. Reaching the mature metacercarial stage is of vital importance. All immature developmental stages within the second intermediate host that are ingested by a definitive host 
will not contribute to the adult generation. The dramatic increase in the parasite's development rate at intermediate temperatures boosts the number of fully developed, and thus infective, metacercariae present in a system. An acceleration of the life cycle and a concomitant enhanced impact of parasites could be the consequence, which has already been shown to occur under conditions of increased temperature in some ecosystems (Marcogliese 2001, Kutz et al. 2005).

\section{Net effects of temperature}

Three main net effects of temperature on this trematode-amphipod system can be described (see Table 3), assuming that no other ecological factor changes in a way that influences the inferences made. First, at temperatures below $20^{\circ} \mathrm{C}$, the production, emergence and infectivity of cercariae are relatively low, but the survival period of cercariae is prolonged. The survival and, therefore, availability of amphipod hosts is greatest at these temperatures; thus infections in second intermediate hosts are persisting at constant but low levels without having a major impact on the amphipod population. This is currently the prevailing condition. Second, at intermediate temperatures $\left(20\right.$ to $\left.25^{\circ} \mathrm{C}\right)$, the production and emergence of cercarial transmission stages are substantially increased, the survival of the cercariae is relatively long and their infectivity is at a maximum. Amphipod survival is considerably diminished at these temperatures, whereas parasite development within amphipods is greatly accelerated. These conditions seem to be optimal for acceleration and completion of the life cycle by a greater number of individual parasites. Water temperatures between 20 and $25^{\circ} \mathrm{C}$ and above are occurring at present during summer days at low tide (A. Studer unpubl. data). Thus, we predict that the parasite will find such optimal conditions more often and for longer periods of

Table 3. Net effects of temperature: summary of results. The number of ' + ' indicates the relative magnitude of the positive effect of temperature on each step of the transmission process from first to second intermediate host. '-' indicates a strong negative effect. For cercarial output, only effects of acclimatisation temperatures are shown

\begin{tabular}{|lcccccc|}
\hline \multirow{2}{*}{ Parameter } & \multicolumn{6}{c}{ Temperature $\left({ }^{\circ} \mathrm{C}\right)$} \\
& 16 & 20 & 25 & 30 & 34 \\
\hline Cercarial output & + & ++ & +++ & ++ & \\
Cercarial survival & +++ & ++ & ++ & + & + \\
Cercarial infectivity & + & ++ & +++ & ++ & + \\
Amphipod susceptibility & + & + & + & + & + \\
Amphipod survival & +++ & ++ & ++ & - & - \\
Parasite development & + & ++ & +++ & - & - \\
within amphipod & & & & & \\
\hline
\end{tabular}

time with global warming. Under such conditions, the impact of the parasite on a host population could be substantial, as massive infection events and, therefore, parasite-induced mortality could lead to rapid reductions in amphipod populations in places where infection prevalence in first intermediate snail hosts is high (Fredensborg et al. 2004). Such an additive effect of temperature and parasitism has been observed in another intertidal trematode-amphipod system, and the resulting mass mortality of the amphipod hosts caused substantial ecosystem-wide consequences (Jensen \& Mouritsen 1992, Mouritsen \& Jensen 1997). Third, at high temperatures $\left(\sim 30^{\circ} \mathrm{C}\right.$ and above), relatively high numbers of cercariae are still being produced but their infectivity is low and their functional life span very short. More importantly, the survival of amphipod hosts at these temperatures is even lower. From the parasite's perspective, successful transmission is reduced but might still be possible. The high mortality of amphipods, however, could mean that hosts (individuals and populations) may not be available for infection or not be available long enough for the completion of the parasite's development. A disruption of the host-parasite relationship could result. At present, this is rarely an issue. However, predicted changes include an increase in the number of high temperature episodes (Ministry for the Environment 2008), thus increasing the risk of temperature-induced amphipod mortality and the concomitant disruption of this host-parasite system.

Although temperature is a very important factor, host-parasite systems are influenced by a large and complex network of abiotic and biotic factors that could significantly alter predicted outcomes solely based on responses to constant temperatures in laboratory settings. For example, biotic interference in parasite transmission could reduce the number of cercariae present in a system due to simultaneous increases in the feeding activity of the organisms that prey on them (Thieltges et al. 2008). Also, temperature variability has been shown to increase parasite development when compared with constant temperature for temperatures below $21^{\circ} \mathrm{C}$, and to slow parasite development above $21^{\circ} \mathrm{C}$ (Paaijmans et al. 2009). In our experiments, the temperature boost to which half of the infected snails were exposed during incubation (for the other half, incubation temperature = acclimatisation temperature) had a significant positive effect on the production and output of cercarial transmission stages at all temperature levels investigated, giving credence to the importance of considering temperature variability. Furthermore, temperature or other factors such as a rise in sea level or habitat alterations might influence the distribution and behaviour of hosts, especially the definitive bird host, thereby altering parasite recruit- 
ment or hindering the completion of the life cycle due to changes in feeding patterns. Finally, since global warming will occur over numerous host and parasite generations, it is possible that natural selection will favour genotypes with certain responses to temperature over other genotypes. Such multi-year evolutionary considerations cannot be addressed within the context of an experiment, but they imply that the characteristics of organisms that might exist in a warmer future environment may differ from those that exist in the present climate.

In conclusion, our results indicate that temperature strongly, but differentially, affects the different steps of the transmission and infection processes of the hostparasite system studied, pointing to the second intermediate amphipod host as the most vulnerable step overall. Based on our results, we predict that the transmission and development of this parasite will be positively affected by increasing temperatures, as long as temperatures lie within the optimal range for the parasite and its hosts. Amphipods are likely to be exposed more often to a greater number of parasites, thereby increasing the risk of parasite-induced mortality. Under extreme conditions such as heat waves, parasite transmission might be reduced, but the risk of temperature-induced mortality of amphipods is most pronounced, potentially leading to a disruption of this link in the completion of the parasite's life cycle. As studies from another amphipod-trematode system point to similar temperature sensitivity (e.g. Jensen \& Mouritsen 1992, Mouritsen \& Jensen 1997), intertidal amphipod populations may generally experience increasing parasite pressure under climate change. Given the pivotal role of amphipods as decomposers, prey and ecosystem engineers in many intertidal systems (e.g. Mouritsen et al. 1998), this may have far-reaching effects for these ecosystems. The inclusion of all stages of the transmission process from first to second intermediate host and the evaluation of net effects are valuable tools for attaining a more realistic understanding of the possible impacts of climate change on parasitism and host-parasite interactions. However, long-term monitoring programs are required to verify the predictions made here and to provide data on the actual interactions between environmental conditions and host-parasite relationships in ecosystems affected by climate change.

Acknowledgements. We are grateful to all anonymous reviewers and the members of Otago University's Ecological Parasitology Lab for invaluable comments on earlier versions of the manuscript. Thanks to K. Garrett for technical and logistical assistance regarding the experimental setup and to I. Ruza for assistance with field collections and the experimental setup. Long-term data on sea temperatures in the Otago Harbour were provided by the Portobello Marine Lab. This research was funded by the University of Otago, New Zealand, and the Department of Zoology in particular, for postgraduate research by A.S. D.W.T. acknowledges support from a fellowship from the German Research Foundation (Th 1361/1-1).

\section{LITERATURE CITED}

Ataev GL (1991) Temperature influence on the development and biology of rediae and cercariae of Philophtalmus rhionica (Trematoda). Parazitologiya 25:349-359

Bryan-Walker K, Leung TLF, Poulin R (2007) Local adaptation of immunity against a trematode parasite in marine amphipod populations. Mar Biol 152:687-695

Chubb JC (1979) Seasonal occurrence of helminths in freshwater fishes. Part II. Trematoda. Adv Parasitol 17:141-313

de Wilde PAWJ, Berghuis EM (1978) Cyclic temperature fluctuations in a tidal mud-flat. In: Naylor E, Hartnoll RG (eds) Cyclic phenomena in marine plants and animals. Pergamon Press, Oxford, p 435-441

Esch GW, Gibbons JW, Bourque JE (1975) An analysis of the relationship between stress and parasitism. Am Midl Nat 93:339-353

Evans NA (1985) The influence of environmental temperature upon transmission of the cercariae of Echinostoma liei (Digenea, Echinostomatidae). Parasitology 90:269-275

Evans NA, Gordon DM (1983) Experimental studies on the transmission dynamics of the cercariae of Echinoparyphium recurvatum (Digenea, Echinostomatidae). Parasitology 87:167-174

Fredensborg BL, Mouritsen KN, Poulin R (2004) Intensitydependent mortality of Paracalliope novizealandiae (Amphipoda, Crustacea) infected by a trematode: experimental infections and field observations. J Exp Mar Biol Ecol 311:253-265

Fredensborg BL, Mouritsen KN, Poulin R (2005) Impact of trematodes on host survival and population density in the intertidal gastropod Zeacumantus subcarinatus. Mar Ecol Prog Ser 290:109-117

Fredensborg BL, Mouritsen KN, Poulin R (2006) Relating bird host distribution and spatial heterogeneity in trematode infections in an intertidal snail — from small to large scale. Mar Biol 149:275-283

Harvell CD, Kim K, Burkholder JM, Colwell RR and others (1999) Emerging marine diseases: climate links and anthropogenic factors. Science 285:1505-1510

- Harvell D, Altizer S, Cattadori IM, Harrington L, Weil E (2009) Climate change and wildlife diseases: When does the host matter the most? Ecology 90:912-920

Jensen KT, Mouritsen KN (1992) Mass mortality in two common soft-bottom invertebrates, Hydrobia ulvae and Corophium volutator - the possible role of trematodes. Helgol Mar Res 46:329-339

Keeney DB, Waters JM, Poulin R (2007) Diversity of trematode genetic clones within amphipods and the timing of same-clone infections. Int J Parasitol 37:351-357

> Kutz SJ, Hoberg EP, Polley L, Jenkins EJ (2005) Global warming is changing the dynamics of Arctic host-parasite systems. Proc R Soc Lond Ser B 272:2571-2576

Lafferty KD, Porter JW, Ford SE (2004) Are diseases increasing in the ocean? Annu Rev Ecol Evol Syst 35:31-54

Lafferty KD, Allesina S, Arim M, Briggs CJ and others (2008) Parasites in food webs: the ultimate missing links. Ecol Lett 11:533-546

> Lauckner G (1987) Ecological effects of larval trematode infestation on littoral marine invertebrate populations. Int J Parasitol 17:391-398 
Marcogliese DJ (2001) Implications of climate change for parasitism of animals in the aquatic environment. Can J Zool 79:1331-1352

Marcogliese DJ (2004) Parasites: small players with crucial roles in the ecological theater. EcoHealth 1:151-164

Martorelli SR, Fredensborg BL, Mouritsen KN, Poulin R (2004) Description and proposed life cycle of Maritrema novaezealandensis n. sp. (Microphallidae) parasitic in red-billed gulls, Larus novaehollandiae scopulinus, from Otago Harbor, South Island, New Zealand. J Parasitol 90: 272-277

McCarthy AM (1999) The influence of temperature on the survival and infectivity of the cercariae of Echinoparyphium recurvatum (Digenea, Echinostomatidae). Parasitology 118:383-388

Meißner K, Bick A (1999a) Laboratory studies of parasite transmission aspects between Hydrobia spp. (Gastropoda) and Corophium volutator (Amphipoda). Int Rev Hydrobiol 84:61-72

Meißner K, Bick A (1999b) Mortality of Corophium volutator (Amphipoda) caused by infestation with Maritrema subdolum (Digenea, Microphallidae) - laboratory studies. Dis Aquat Org 35:47-52

Ministry for the Environment (2008) Climate change effects and impacts assessment: a guidance manual for local government in New Zealand, 2nd edn. Ministry for the Environment, Wellington

Mouritsen KN (2002) The Hydrobia ulvae-Maritrema subdolum association: influence of temperature, salinity, light, water pressure and secondary host exudates on cercarial emergence and longevity. J Helminthol 76: 341-347

Mouritsen KN, Jensen KT (1997) Parasite transmission between soft-bottom invertebrates: temperature mediated infection rates and mortality in Corophium volutator. Mar Ecol Prog Ser 151:123-134

Mouritsen KN, Poulin R (2002) Parasitism, community structure and biodiversity in intertidal ecosystems. Parasitology 124:S101-S117

Editorial responsibility: Hans Heinrich Janssen, Oldendorf/Luhe, Germany
Mouritsen K, Mouritsen L, Jensen K (1998) Change of topography and sediment characteristics on an intertidal mudflat following mass-mortality of the amphipod Corophium volutator. J Mar Biol Assoc UK 78:1167-1180

> Mouritsen KN, Tompkins DM, Poulin R (2005) Climate warming may cause a parasite-induced collapse in coastal amphipod populations. Oecologia 146:476-483

Paaijmans KP, Read AF, Thomas MB (2009) Understanding the link between malaria risk and climate. Proc Natl Acad Sci USA 106:13844-13849

> Pechenik JA, Fried B (1995) Effect of temperature on survival and infectivity of Echinostoma trivolvis cercariae: a test of the energy limitation hypothesis. Parasitology 111: 373-378

> Pietrock M, Marcogliese DJ (2003) Free-living endohelminth stages: at the mercy of environmental conditions. Trends Parasitol 19:293-299

Poulin R (2006) Global warming and temperature-mediated increases in cercarial emergence in trematode parasites. Parasitology 132:143-151

Poulin R, Morand S (2000) The diversity of parasites. Q Rev Biol 75:277-293

> Poulin R, Mouritsen KN (2006) Climate change, parasitism and the structure of intertidal ecosystems. J Helminthol 80:183-191

Sousa WP (1991) Can models of soft-sediment community structure be complete without parasites? Am Zool 31:821-830

Thieltges DW, Rick J (2006) Effect of temperature on emergence, survival and infectivity of cercariae of the marine trematode Renicola roscovita (Digenea: Renicolidae). Dis Aquat Org 73:63-68

> Thieltges DW, Jensen KT, Poulin R (2008) The role of biotic factors in the transmission of free-living endohelminth stages. Parasitology 135:407-426

Thomas F, Renaud F, Guegan JF (eds) (2005) Parasitism and ecosystems. Oxford University Press, Oxford

Ward JR, Lafferty KD (2004) The elusive baseline of marine disease: Are diseases in ocean ecosystems increasing? PLoS Biol 2:542-547

Submitted: March 5, 2010; Accepted: July 19, 2010

Proofs received from author(s): September 3, 2010 